\section{Digital Avionics-The Best Is Yet To Come!!!}

CARY R. SPITZER, Senior Member, IEEE

NASA-Langley Research Center

This paper reviews some of the history and background of digital avionics and offers some tantalizing possibilities for the future. There are payoffs in many areas from digital avionics; however, the ultimate benefits are increased mission effectiveness and lower costs. Two major U.S. Air Force avionics programs designed to increase mission effectiveness are reviewed. Major barriers to the expanded use of digital avionics in civil transports as a means to lower operating costs are examined. The paper also examines lightning effects, architectures, optical components, displays, and voice interactive control which are current research areas that promise to yield significant advances for digital avionics systems. Finally, in a notice of optimism, it is concluded that the best is yet to come. As good as contemporary avionics are, we have only begun to visualize their ultimate potential.

Manuscript received January 23, 1984; revised March 5, 1984.

Author's address: NASA-Langley Research Center, MS 472, Hampton, VA 23665.

U.S. government work not protected by U.S. copyright.

\section{INTRODUCTION}

Digital avionics is the youngest and newest member of the aeronautical technologies team which already includes aerodynamics, structures, materials, and propulsion. Like the space age, digital avionics is about a quarter of a century old. From an unheralded beginning, in less than 25 years digital avionics has emerged as a major force in aeronautics.

In general, advances in digital avionics have paralleled advances in microelectronics. The explosive growth in computational capability and the dramatic, unprecedented drop in weight, power, and relative cost, especially in the last decade, have fostered the application of electronics to previously undreamed of aeronautical tasks. Concurrent with this growth in computational power has been the equally important emergence of highly versatile electronic displays and input/output devices.

Initially digital avionics performed the traditional functions of navigation, communications, and fire control. Then, as the capabilities of digital avionics grew, more important tasks were assigned. By 1974 a full authority, single channel digital automatic flight control system was flying on a JA-37 fighter built by SAABScania. In the last decade nine more digital fly-by-wire (DFBW) systems have entered service [1]; see Fig. 1. All of these systems, with the exception of the Space Shuttle, have mechanical backup. Research and development DFBW systems without mechanical backup include the F-8 DFBW, Jaguar DFBW, and the AFTI/F-16. (The issue of mechanical backup for DFBW is an extremely important one and is examined in detail later.)

The first operational, domestic military aircraft to use "digital control by wire" is the F/A-18. This system is not entirely digital; it has analog sensors and actuators and retains a mechanical backup for control of the stabilator surfaces; however, it is considered to be a DFBW system. Experience to date has shown the system to be very reliable and extremely versatile. This versatility was clearly demonstrated during early flight testing when several handling quality problems were solved through very modest software changes [2]. No hardware or structural changes were needed to solve these problems, which is in sharp contrast to previous aircraft development programs.

Digital avionics have also entered the civil arena. Since 1980 several commercial transports that make extensive use of digital avionics have begun revenue service. How well the avionics works is best captured by the following quotation from E.L. Webb, Vice President for Engineering, Boeing Commercial Airplane Company [3]:

One of the most pleasant surprises has been the universal acceptance of the airplanes and their digital avionics by flight crews, cabin attendants, maintenance crews, and passengers. After a few "teething" problems the digital avionics systems have 


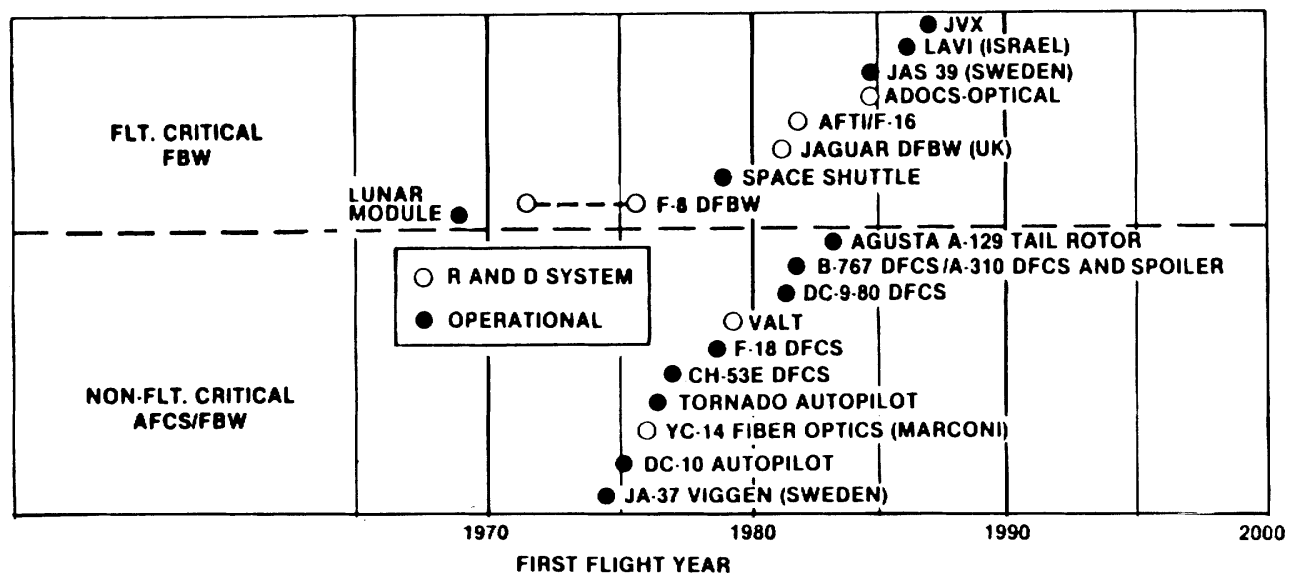

Fig. 1. Evolution of digital flight control systems [1].

worked much better than expected. Reliability has been excellent with some operators consistently over 98 percent. The MTBFs after one year in service exceed expectations by a wide margin. As an example, United had accumulated over $18000 \mathrm{~h}$ before experiencing an inertial reference unit (IRU) failure.

Another civil transport aircraft on the horizon will make even greater use of digital avionics. The Airbus A320 will have quadruple redundant DFBW with dissimilar redundancy in hardware and software. The aircraft also will use active controls technology to reduce fuel consumption. Mechanical backup will be provided for the rudder and pitch trim.

\section{WHY DIGITAL AVIONICS?}

The previous discussions demonstrate the expanding use of digital avionics. Some of the reasons for incorporating this technology already have been alluded to, but they need more detailed examination.

The basic payoff for using digital avionics depends on the aircraft mission. In the military arena they yield enhanced combat effectiveness, and in the civil arena they yield reduced operating costs. These payoffs are realized by the application of the attributes of digital avionics systems, specifically increased reliability, survivability, flexibility, maintainability, and availability.

There is very limited published data on digital avionics reliability in service. Many promises for enhanced reliability were made prior to delivery of the latest commercial transports, and the promises apparently are being kept. Table I summarizes some representative data [4]. Similar data on the total avionics suite on fighter aircraft shows equally impressive gains. Through 1980 for the analog avionics on the F-4E the mean flight hours between failures (MFHBF) is 1.9, while for the digital avionics on the F-15 the MFHBF is 4.2, a 2.2:1 gain [5]. More recent data which compare the same aircraft and the F-18 to the F-4J show a 3:1 or better improvement in MTBF for the digital equipment. It is important to keep
TABLE I

Comparison of MTBR and MTBF for Similar Equipment on the B-747 and B-767

\begin{tabular}{llcc}
\hline \hline & & MTBR & MTBF \\
\multicolumn{1}{c}{ B-747 } & B-767 & $747: 767$ & $747: 767$ \\
\hline Central air data computer & digital air data computer & $1: 3.0$ & $1: 3.0$ \\
$\begin{array}{l}\text { Inertial navigation unit } \\
\text { Pitch and roll computer } \\
\text { with calibrators }\end{array}$ & inertial reference unit & $1: 2.0$ & $1: 2.5$ \\
& flight control computer & $1: 2.5$ & $1: 2.0$ \\
\hline
\end{tabular}

Notes: T.M. Barry [4] is the reference for this material.

in mind, however, the more stringent reliability requirements applied to the digital equipment compared with the analog equipment 20 years ago. Had these current requirements been applied to the analog equipment, its reliability would have been better. Recent experience on the analog avionics equipped F-16 is $7.3 \mathrm{~h}$ MTBF [6].

Survivability remains an unknown in military aircraft because of the lack of combat experience; however, it is widely accepted that digital avionics are more survivable, mainly because of reconfigurability.

Flexibility of digital avionics has been unequivocally demonstrated by the relative ease of software fixes during developmental testing. The F-18 experience has already been described [2]. For civil transports flexibility also has been demonstrated during developmental testing, both on Boeing and Airbus Industrie airplanes [7, 8].

Built-in test features on digital avionics dramatically ease the maintenance task. In-flight faults are automatically recorded for later playback on the ground by maintenance personnel. These data, coupled with built-in diagnostic procedures, expedite maintenance procedures and reduce false alarm removals.

Availability of civil transport aircraft using digital avionics has proven to be high. Airlines refer to it as dispatchability, and for one operator dispatchability from the beginning of revenue service has been as high as that of some mature aircraft in their fleet.

As beneficial as this current generation of digital avionics has proven to be, the ultimate gains possible 
from their use promise to be even greater. The remainder of the paper examines some major programs and research that will make giant strides toward these ultimate gains.

\section{MAJOR U.S. AIR FORCE PROGRAMS BEING FORMULATED}

Defense needs historically have been the major force behind many of the advances in avionics as well as other aeronautical technologies. For the defense community there is a continuing need for what is commonly referred to as "more bang for the buck" or more formally referred to as "increased mission effectiveness." Today in the Department of Defense there are a number of avionics research and development programs focused on the objective of increased mission effectiveness. The two Air Force Wright Aeronautical Laboratories initiatives described below are representative of these programs.

PAVE PILLAR has as its objective the development of the next generation of integrated avionics systems: a fully integrated avionics suite that would dramatically improve the MTBF and increase the daily sortie rate for fighters by approximately 50 percent [6]. Two of the most promising technologies being examined in PAVE PILLAR are very high speed integrated circuits (VHSIC) and voice interactive controls. The program is completing the definition phase leading to the design and development of prototype flight hardware during 19851990. If applied to the F-16 of today, PAVE PILLAR is predicted to yield a 45 percent increase in sortie rate and to improve the avionics system MTBF from $7.3 \mathrm{~h}$ to $35 \mathrm{~h}$ [6].

A complementary avionics research initiative entitled self-repairing flight control system focuses on developing technology for real-time reconfiguration of the flight control systems as a means of overcoming the effects of battle damage [9]. Specific performance goals for the flight control system include a factor of 10 reduction in the probability of loss from combat causes and at least a actor of 10 improvement in the MTBF.

\section{BIG PAYOFF IN CIVIL FLIGHT CRITICAL DIGITAL AVIONICS}

Recent studies have projected fuel savings of over 10 percent if a flight critical active control system without mechanical backup were to be installed in 350 passenger, 3 engine, long-range advanced technology transport. More modest savings would be achieved if such a system were applied to a contemporary 200 passenger, twin engine, medium range transport [10]. Coupling a flight critical active control system with an all-electric aircraft (one in which all pneumatic and hydraulic functions have been replaced by electrically driven ones) could raise these projected savings to as much as $17-18$ percent) [10].

The key term in the previous paragraph is "flight critical." For civil transports the FAA has defined flight critical to mean that failure of such a system or piece of equipment would unequivocally result in the loss of the aircraft. Failure of flight critical avionics must be "extremely improbable," which is generally considered to be probability of one failure in a billion $\left(10^{9}\right)$ flight hours [11]. Military aircraft have a goal of 1 failure in 10 million $\left(10^{7}\right)$ flight hours for flight critical avionics.

Although the reliability performance requirement of a flight critical system has been quantified, the techniques for demonstrating achievement of that performance are lacking. There are no techniques presently available that can prove beyond a reasonable doubt that a given flight control system has achieved its reliability requirement, especially at the $P_{f}=10^{-7}$ to $10^{-9} / \mathrm{h}$ level. It is widely accepted that flight critical systems can be designed and built, but the techniques to demonstrate achievement of the reliability goal still require major research to realize. A number of laboratories are now examining highly reliable systems assessment, verification, and validation methodologies, but acceptable, proven methodologies are 3-7 years away.

\section{SOME CURRENT RESEARCH AREAS}

\section{Lightning}

A continuing special concern for digital avionics is the effect of lightning and other electromagnetic interference (EMI) hazards. Experience to date on commercial transports has shown an excellent tolerance by the avionics to lightning strikes to the aircraft. P. Potocki of Airbus Industrie reports when lightning strikes the A300B4 with digital equipment it is common for "the avionics to recover before the crew" [12]. The cause for continuing concern despite the current (no pun intended) performance is the growing use of composites on airplanes as a weight-saving measure. As the composites replace traditional aluminum applications, especially the airplane skin, the shielding effect is lost and wiring is at much greater risk to induced spurious signals from the environment.

The Atmospheric Electrical Hazards Program has been jointly established by the Air Force, Army, Navy, Defense Nuclear Agency, FAA, and NASA to explore and understand all facets of lightning and other EMI sources as they affect digital avionics [13]. A key element of this program is an instrumented F-106 airplane that penetrates thunderstorm cells and records data from lightning strikes to the airplane. In 1983 the airplane received 130 direct strikes.

\section{Architectures}

There is no perfect architecture-only an optimum one for a given avionics system. Architecture is driven by a gamut of factors including reliability, certificability, survivability, maintainability, and, of course, cost. These 
factors and all other relevant ones need to be applied in priority order to a candidate architecture to assess its suitableness. A representative current architecture, that of the F-18 [2], is shown in Fig. 2.

Ongoing research in data buses and protocols and reconfigurable systems holds the promise of less complex but more flexible architectures. An example of an architecture for a future civil transport [14] is shown in Fig. 3. This architecture clearly portrays the "central nervous system" concept frequently espoused by preliminary design specialists. It is interesting to examine the two design approaches for driving actuators as portrayed on the elevators. On the right elevator there are 4 actuators, 2 per elevator, each driven by a separate bus. On the left elevator there are 6 actuators, 3 per elevator, with each of 3 buses driving 2 actuators. This difference in design approaches highlights the diversity of available options and the lack of a single, proven, preferred design. Note also the turboprop engines.

Reconfigurable controls research builds on principles of expert systems. The near-term goal is the design of reconfigurable flight control systems and the development of automatically selectable flight control algorithms that compensate for control effector failures. Systems with this capability are one of the objectives of the self- repairing flight control system reliability and maintainability initiative discussed earlier [9]. The longterm goal is flight control systems that employ true artificial intelligence.

\section{Optical Buses and Active Elements}

The EMI immunity and large bandwidth of optical materials suggests the potential for expanded use in digital avionics. The YC-14 used an optical link between flight control computers when it flew in 1976. Currently the Army is developing the advanced digital optical control system (ADOCS) scheduled to fly later this year on a Sikorksy UH-60A Black Hawk [15]. Research continues with emphasis on developing optical computers and practical, low-loss connector and splicing technology that can be made rugged for widespread airborne applications. Because of these splicing and connector problems current fiber optics are most appropriate for point-to-point wideband bulk distribution of data as opposed to the collection and distribution of data for individual computers, sensors, and actuators. There are conflicting claims concerning the weight of fiber optics, however. Some experts believe that fiber optics offer no weight advantage over wires because of the relatively

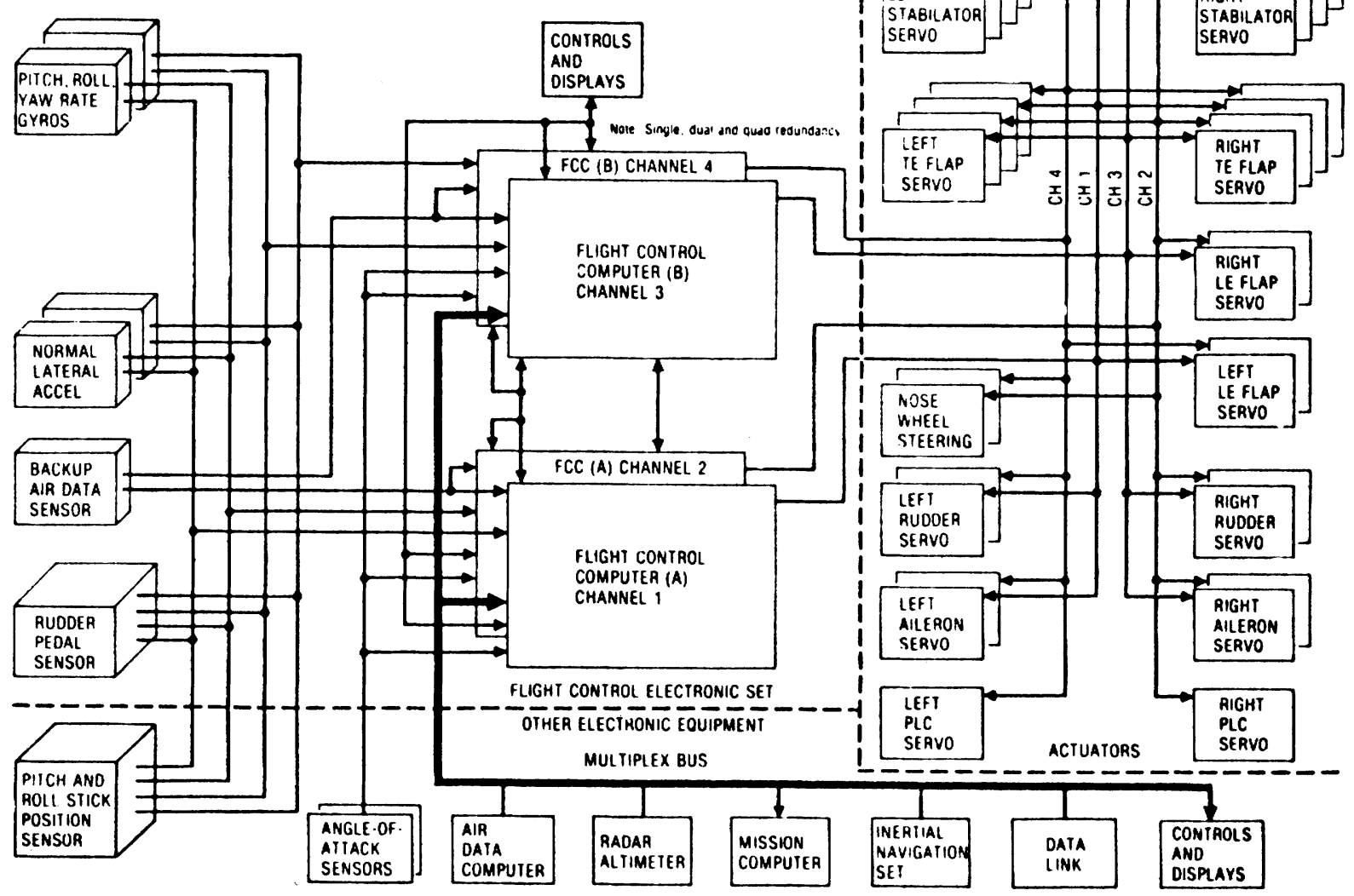

Fig. 2. F/A-18 flight control electric set interface [2]. 


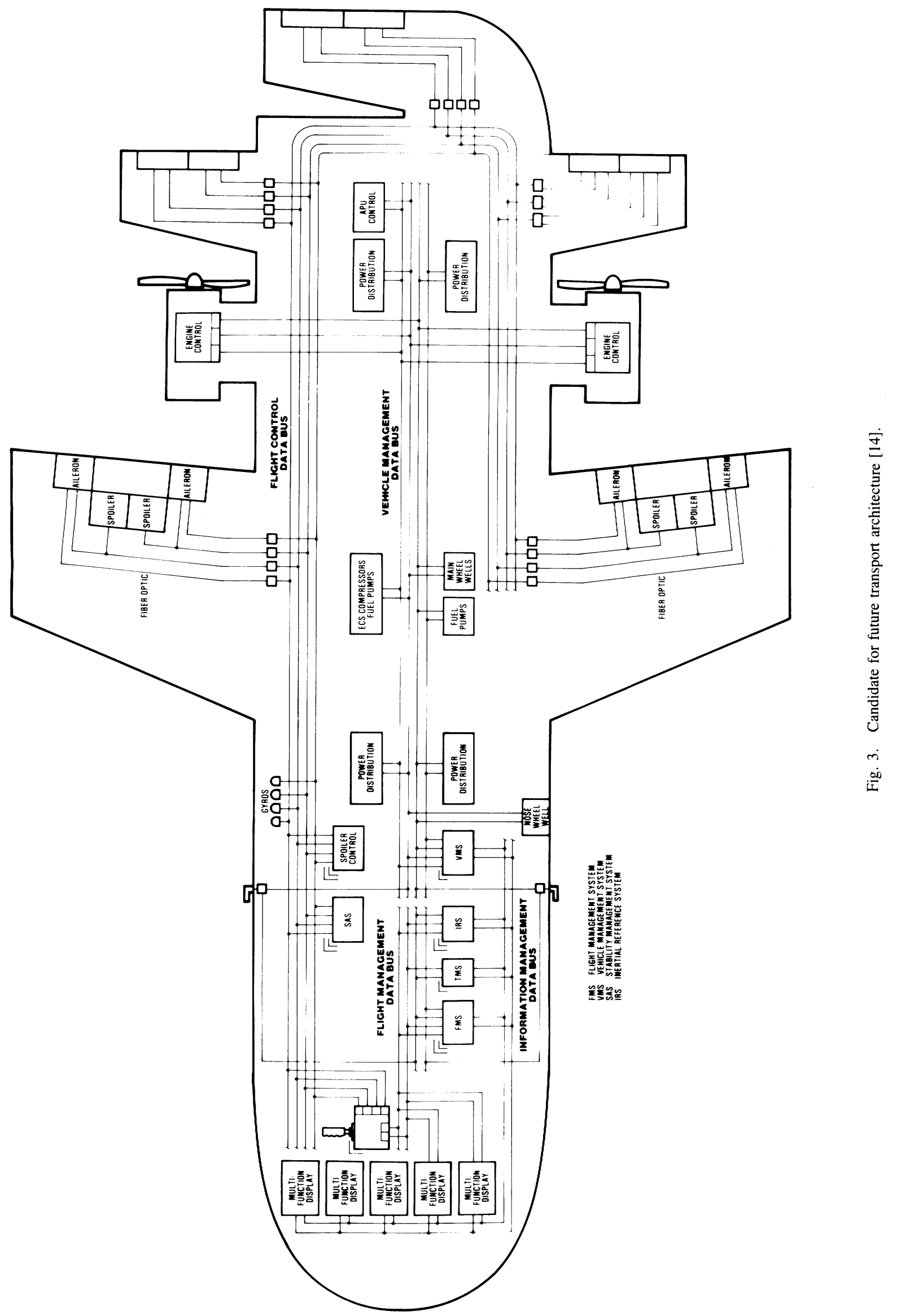


heavy (when properly shielded) signal conditioning electronics required at each terminal.

\section{Displays and Input/Output Devices}

As microelectronics capabilities have advanced during the last decade there also has been advancement in display technology. Electromechanical indicators and rows of single function switches have been superseded by CRT displays and multifunction keyboards with greatly expanded capability. Modern fighters such as the F-15, F16 , and F-18 use high brightness and high resolution monochrome CRTs, and modern transports such as the MD-80, B-767, B-757, and A-310 use color CRTs. The display formats can be changed and optimized as a function of mission phase. This same flexibility is now appearing in multifunction keyboards where a single switch or button can perform a wide range of functions throughout the mission.

CRTs have proven to be a major improvement in display technology; however, they should be viewed only as transitory on the way to the ultimate flat panel displays. The reduced volume and power of flat panel displays coupled with intrinsic digital compatibility are strong drivers toward this type of display as the wave of the future. A thin film monochromatic electroluminescent display with 68 lines/inch resolution and capable of being driven at video rates already has been demonstrated [16]

\section{Voice}

Today voice is the least used control technique. This situation is rapidly changing, and it probably can be safely said that voice research is the fastest growing area of digital avionics. Voice recognition and voice synthesis is being explored for potential application to many types of aircraft: fighters, helicopters, general aviation, and civil transports. Initial flight evaluation in the AFTI F-16 of a voice control system for noncritical functions has been successfully completed [17]. Voice control techniques also have been demonstrated on the Princeton University NAVION [18]. These tests are only the beginning and by the end of the decade voice probably will be a widely accepted control technique.

\section{THE BEST IS YET TO COME}

Digital avionics will continue to feed on the cornucopia of electronics technologies. Avionics alone is not a large enough market to force technology advances, but it can reap the benefits of the advances that other markets cause.

Black boxes are on the way out. New packaging concepts are already being explored. Single cards, with built in batteries for reserve power, will replace the black boxes of today and these cards will be mounted in a smaller, cooler avionics bay. The bay may be broken into several smaller, refrigerated bays distributed throughout the aircraft.

Maintenance will take on a different flavor as built-intest continues to simplify it. Only the data and power buses, sensors, and actuators will require the traditional maintenance tasks of repair or replacement and checkout. The cards that have replaced the black boxes will have become so inexpensive that they can be replaced either in a preventive maintenance fashion or on condition, whichever is economically and operationally attractive.

Reliability of the flight control system will no longer be an issue. Fault tolerant concepts and their associated assessment and validation concepts will have been proven beyond all reasonable doubt. Implementation of flight critical digital avionics will be as straightforward as bellcranks and cables are today. Failed computers will be of no greater consequence than failed light bulbs and will be replaced as discussed in the previous paragraph.

Equally dramatic changes are in store for the cockpit. Voice control, as promising and intriguing as it is, is only transitory. By the turn of the century biocybernetics, the concept of using physiological sensors to monitor the internal state of the human operator, may be commonplace, at least in high performance aircraft. Biocybernetics will be applied to realize the ultimate coupling between the pilot and the aircraft. It has been suggested that biocybernetics even could be used to detect brain disfunction (in case of injury to the pilot) in which case the aircraft control system would automatically take over and safely return the airplane and pilot to home base [19].

Digital avionics has arrived. It is now a full-fledged member of the aeronautics team and we can now only begin to dream of its ultimate potential. THE BEST IS YET TO COME! 
[10] Letchworth, R. (1983)

[1] Rediess, H.A. (1984)

Technology review of flight crucial flight control systems.

NASA Report CR 172332. Report prepared under Contract NAS1-17403 for NASA Langley Research Center, Hampton. $\mathrm{Va}$.

Informal Report of the All Electric Aircraft Study Team.

NASA-Langley Research Center, Hampton, Va.

reacy, J.J. (1983)

Flight safety issues of an all electric aircraft.

In Proceedings of the 1983 IEEE/AESS Simposium, vol. II, paper 4; reprinted in these Transactions, AES-20, 3 (May 1984), 227-230.

[2] Harschburger, H.E., and Moomaw, R.F. (1983)

Experience with the F/A-18 digital flight control system.

In Proceedings of the 1983 IEEE/AIAA 5th Digital Avionics Systems Conference, pp. 6.1.1-6.1.8.

[3] Webb, E.L. (1983)

New commercial transport airplanes-Digital avionics design decisions.

In Proceedings of the 1983 IEEE/AIAA 5th Digital Avionics Systems Conference, p. 1.3.

[4] Barry, T.M. (1984)

Personal communication.

[5] Little, R.C., Murden, W.P., Schaefer, R.K. (1982)

High technology raises fighter force readiness.

Astronautics and Aeronautics, 20, 6 (June 1982), 38-45, 61.

[6] Kozicharow, E. (1984)

Air Force considers using integrated avionics in F-16.

Aviation Week and Space Technology (Feb. 13, 1984), 160164.

[7] Kosowski, E. (1983)

Perspectives on software development and verification-

Boeing 757/767 AFDS.

In Proceedings of the 1983 IEEE/AIAA 5th Digital Avionics Systems Conference, pp. 6.5.1-6.5.5.

[8] Wills, A.D. (1983)

A310 slat and flap control system management and experience.

In Proceedings of the 1983 IEEE/AIAA 5th Digital Avionics Systems Conference, pp. 6.7.1-6.7.8.

[9] Chandler, P.R. (1984)

Self-repairing flight control system: Reliability and maintainability program plan.

Air Force Wright Aeronautical Laboratories/Flight Dynamics Laboratory/Flight Control Division, Feb. 9, 1984.

Potocki, P. (1982)

Report to the Airlines Electronic Engineering Committee.

73rd General Session (Brussels, Belgium, Nov. 2-4, 1982).

[13] Beavin, R.C., et al. (1983)

Atmospheric electric hazards protection program

In Proceedings of the 8th International Aerospace and Ground Conference on Lightning and Static Electricity (DOT/FAA/CT-83/25, June 21-22, 1983), pp. 2.1-2.10.

Clay, C.W. (1983)

Digital electronic flight decks-The outlook for commercial aviation .

In Proceedings of the 1983 IEEE/AESS Symposium, vol. II, paper 3; reprinted in these Transactions, AES-20, 3 (May 1984), 221-226.

[15] Anonymous (1984)

Aviation Week and Space Technology (Jan. 16, 1984), 174182.

[16] Hatfield, J.J. (1983)

Personal communication.

[17] Smead, F.W. (1983)

Voice-actuated avionics.

Astronautics and Aeronautics, 21, 10 (Oct. 1983), 54-57, 63.

[18] Anonymous (1982)

Aviation Week and Space Technology (Oct. 11, 1982), 135.

[19] Reising, J. (1979)

The crew adaptive cockpit: Firefox here we come.

In Proceedings of the 1979 IEEE/AIAA 3rd Digital Avionics Systems Conference, pp. 204-207.

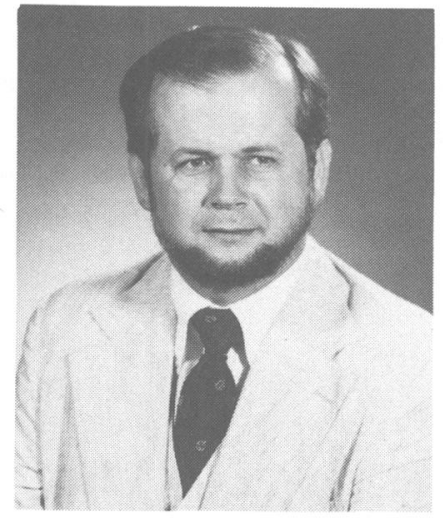

Cary R. Spitzer (S'58-M'60-SM'70) was born in New Hope, Va. He received the B.S. degree in electrical engineering (communications option) from Virginia Polytechnic Institute and State University in 1958 and the M.S. degree in management engineering from George Washington University in 1970.

After service in the Air Force (SAC) as a Communications Operations Officer he joined NASA Langley Research Center in October 1962. Initially, he conducted research on thermal sensors for models being tested in various wind tunnels at Langley. In 1969 he joined the Viking Project Office as Manager of the molecular analysis investigation. Later he served as the Deputy Director for Operations in the Science Analysis and Mission Planning Directorate of the Viking Flight Team and finally as Deputy Viking Project Manager for Langley Research Center operations. In 1978 he joined what is now the Systems Application Office where he is examining the role of avionics in advanced aircraft and spacecraft concepts and defining the NASA avionics research program for the next decade. He holds two patents, has published over 30 papers, and was editor of the book, Viking Orbiter Views of Mars.

Mr. Spitzer is a Past President and Life Member of the IEEE Aerospace and Electronic Systems Society and has served on a number of IEEE national boards and committees. In 1984 he received an IEEE Centennial Medal. He is a member of the American Association for the Advancement of Science and participates in the Media Resource Service of the Scientists' Institute for Public Information. He is President of the First Mars Landing Society and is past Chairman of the Langley Colloquia Committee. 